\section{The Detector}

Circuit Description.-Two transistors are used in a Darlington connection to provide a high gain. When the resistance between the input terminals $T 1$ and T2 (see fig.) is lowered the transistor collector currents increase and one coil of the remanent relay $\mathrm{RL}$ is energized and opens both sets of contacts. The relay remains in this state even if the coil current returns to zero. The contacts RL2 are connected in series with the battery supply to an electric clock and contacts RLl are connected in series with the internal batteries. The unit, therefore, consumes no current except during the very short time that the relay contacts are actually changing over. When the resistance at the input terminals is raised again the contacts of the remanent relay may be closed by pressing the reset button, which switches the relay back to its resting state.

Operating Instructions.-The sensing pad is connected to push-type terminals on one side of the unit and the clock battery supply is broken through a two-pin plug. If the pad is dry the input terminal resistance is high and the clock will start when the reset button is pressed. The sensitivity control VR1 sets the terminal resistance at which the unit operates.

1 Willington, F. L., Gerontologica Clinica, 1969, 2, 330.

2 Willington, F. L., personal communication.

J. A. C. BALL, M.D., F.R.C.P., Consultant Physician

Short Brothers and Harland Ltd., Queens Island, Belfast

M. H. McFADDEN, B.sC., M.I.E.E., Head of Ground Equipment, Electronics Department

\section{Ectopic Pregnancy Despite Intrauterine Contraception: A Clue to Mode of Action of I.U.C.D.s}

The mode of action of intrauterine contraceptive devices (I.U.C.D.s) remains obscure. Vessey et al. ${ }^{1}$ confirmed the report by Lehfeldt et al. ${ }^{2}$ that the proportion of ectopic nidations in cases of failed intrauterine contraception greatly exceeds that in pregnancies in the population at large. In refuting the possibility that intrauterine contraception causes ectopic pregnancy, particularly ovarian pregnancy, Lehfeldt $e t$ al. ${ }^{2}$ stressed that it is merely more effective in preventing normal uterine implantation than ectopic implantation.

\section{Patients}

Between 1 July 1967 and 18 December 1974, 103 patients with ectopic pregnancy were admitted to hospital. There were no deaths. Fourteen of these patients had conceived an ectopic pregnancy with an I.U.C.D. in place. The sites of the pregnancies, as noted at laparotomy or laparoscopy, are shown in the fig. Those ectopic pregnancies occurring despite the use of an I.U.C.D., and accurately located, appeared to be confined to the ovary, tubal infundibulum, whence some had been extruded as tubal abortions, and tubal ampulla. Statistical evaluation is precluded by the small number of patients.

\section{Discussion}

I.U.C.D.s neither stop ovulation ${ }^{3}$ nor interfere with sperm invasion of the oviducts. ${ }^{4}$ In a study of a large series of women using I.U.C.D.s, Lehfeldt $e t$ al. ${ }^{2}$ showed that they reduce normal uterine pregnancy by about $99.5 \%$, tubal pregnancy by $95 \%$, but ovarian nidation not at all. Discussing the anti-fertility effect of intrauterine contraception-maximal in the endometrial cavity, weaker in the tubes, but absent in the ovaries-these workers postulated some enzymatic or other chemical action, possibly by retrograde flow from endometrium to tubes. When this is related to the sites of the ectopic pregnancies in this series of patients fitted with an I.U.C.D. the following possibilities arise: effective intrauterine contraception inhibits ovum migration along the oviduct with the production of an anti-fertility state, though not to the absolute exclusion of an occasional ovarian pregnancy; failed intrauterine contraception permits essenti-

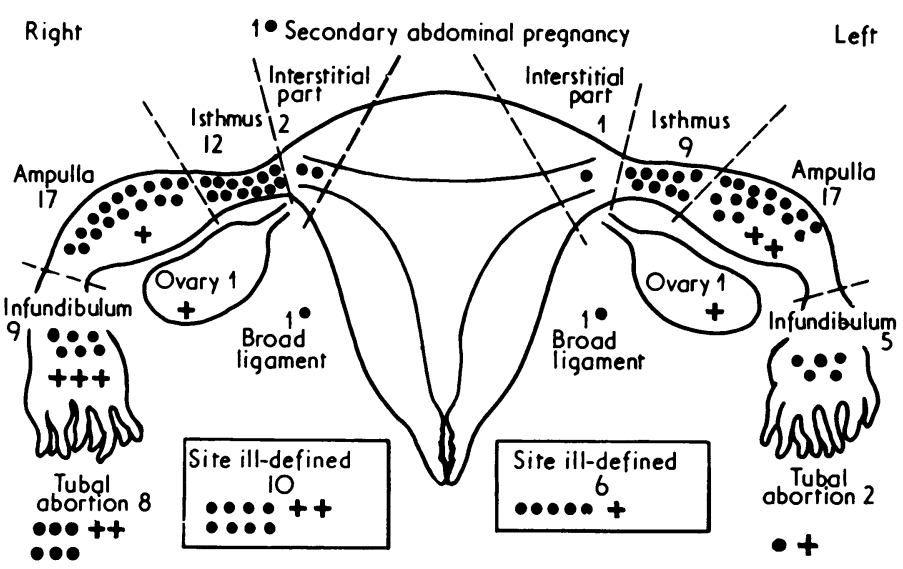

Sites of 103 ectopic pregnancies noted at laparotomy or laparoscopy. $\mathbf{O}=$ No I.U.C.D. in situ. $+=$ I.U.C.D. in situ.

ally normal fertilization but with an incidence thereafter of ectopic, mainly tubal implantation by reason of disturbed ovum migration along the Fallopian tube. Many more patients with ectopic pregnancies despite intrauterine contraception should be studied to confirm this impression.

I thank my gynaecological and surgical consultant colleagues for access to case notes, and Miss Joy Graham for the illustration.

1 Vessey, M. P., et al., Lancet, 1974, 1, 495.

2 Lehfeldt, H., Tietze, C., and Gorstein, F., American Fournal of Obstetrics and Gynecology, 1970, 108, 1005.

${ }^{3}$ Faucher, G. L., et al., American Fournal of Obstetrics and Gynecology, 1969, 104, 502.

${ }^{4}$ Malkani, P. K., and Sujan, S., American fournal of Obstetrics and Gynecology, 1964, 88, 963.

5 Morgenstern, L. L., et al., American fournal of Obstetrics and Gynecology, $1966,96,114$.

Hillingdon Hospital, Uxbridge, Middlesex UB8 3NN

GEORGE JONAS, F.R.C.S., F.R.C.o.G., Consultant Obstetrician and Gynaecologist

\section{Erythrocyte Deformation in Duchenne Muscular Dystrophy}

Using scanning electron microscopy Matheson and Howland ${ }^{\mathbf{1}}$ found an increased proportion of deformed erythrocytes (echinocytes) in patients with various forms of muscular dystrophy. Miale et al., however, were unable to repeat these results. Matheson and Howland suggested that this might have been due to their small sample size and to technical differences. Since Matheson and Howland ${ }^{1}$ stated that the deformation of erythrocytes was visible on light microscopy the present study of a much larger sample of boys with Duchenne muscular dystrophy, carriers, and controls was undertaken to determine the possible wider application of their findings to the detection of carriers. The effects of technical variations were also examined.

\section{Methods and Results}

Early morning blood samples were obtained from fasting subjects by fingerstabs. Three separate samples were obtained from each person. From each sample three slides were prepared, and from each slide 100 cells were examined in random fields. Thus 900 cells were examined from each person, from which the proportion of deformed cells was estimated. The samples were treated according to the method of Matheson and Howland. 1 After fixation, wet preparations were examined by light microscopy at $\times 625$. 